This document is provided under the UK Open Government Licence for public sector information: http://www.nationalarchives.gov.uk/doc/open-government-licence/ 


\section{The Use of Case Studies in Public Administration Training in Kenya}

by R. J. H. СнамвеRs

CAss studies have been widely accepled as a means of developing judgment and practising decision-making and, although there is variety in the methods of preparation and use favoured by individual tutors, certain techniques are more or less standard practice. These involve the presentation of problem situations to groups of students who discuss them in syudicate and then report back their conclusions. There is a minimum of direction by the tutor, the theory being that the students are men of experience and will learn from the material and from one another.

This approach is valid for adrinistrative students, regardless of how much practical experience thcy have had, but its usefulness must depend to some extent on the amount of relevant experience on which they can draw. What sort of case study material is appropriate, and how it is presented, must be related both to the level of experience of the students and to the training needs that are to be fulfilled. In many developing countries, administrators and managers, sometimes with little or no previous administrative experience, are being trained to take over posts which expatriates would previously only have held after long service and often with higher educational qualifications. In these circumstances, the urgent training needs are not only the usual ones of developing judgment and sound decision-making, vital though these are; there is also a great need for the students to gain skill and confidence in carrying out the actual procedures of the job. To achieve all these objects through the use of case studies, two conditions must be fulfilled: the material of the study must be taken from the job for which the students are being trained; and some problems and excrcises in the study must be handled by students individually, and not only in syndicate.

The techniques of case study selection and presentation that have been evolved along these lines at the Kenya Institute of Administration were developed as an attempt to provide the training required by a particular situation. Towards the end of 1962 , there were two six-months courses in public administration under training. One of these courses consisted of 22 officers with an average age of 30 , an average educational level of a little below Cambridge School Certificate, and several years ${ }^{2}$ field experience. 'Their great needs were to speed up their reading and handling of paperwork and to learn to think and make decisions at a policy level. The other course, of 20 officers, consisted of. recent graduates, with an average age of 26 , most of them with Arts degrees from Makerere College, and with their practical administrative cxperience limited to five months as district officers in the ficld. It was expected that many of these graduates would be posted to ministries, and it was important that they should receive training in central government procedures, in the writing of minutes and letters, and in the analysis and handling of difficult files. These two courses typified the two poles of human resources in many developing countries, which, in an oversimplified form, may be stated as experience without education on the one hand, and education without experience on the other.

Mr. R. J. H. Chambers is a lecturer at the Kenya Institute of Administration. 
To provide case study material for these two sets of different but overlapping training needs, a number of files in the then Ministry of State for Constitutional Affairs and Administration were examined. The ideal requirements were that the files should provide scope for individual exercises as well as group discussions; that they should contain all the information needed for action to be taken; that they should have been handled by officers ranging in rank from Assistant Secretary to Permanent Secretary; that the important relationship between Ministers and Parliamentary Secretaries on the one hand, and civil servants on the other, should be demonstrated; that the situations and problems should be typical and should become more difficult and complex as the study proceeded; and that the cases should be interesting and provocative, with end results that would not already be known to the students.

Through the co-operation and tolerance of officers in the Ministry, two suitable files were found and their contents photocopied, The photostats were copied into stencils. All written comments on the original were also inscribed on the stencils and, sacrificing a little realism, made more legible. A few names were changed, but in most cases the real names were retained. Since many of the officers handling the files were known personally to the students, and were considerably senior to them, the studies held a special fascination. The stencils were duplicated, so that each student could build up his own file. The approach was chronological, the students starting with only a few papers, and being issued with successive batches as the study proceeded.

The first study: "Kariuki's Complaint", ar ises out of the Kenya Emergency, when 'Kariuki' was detained, his 'Temporary Occupation Licence for a plot terminated, and a sum, paid to him by Government, ex gratia, in compensation for the hotel he had built on the plot. On release from detention, he makes a series of written complaints that the termination of his licence was illegal and that the compensation was unfairly assessed. At first the student plays the role of Assistant Secretary, and later of Permanent Secretary. In its early stages, the case involves a useful exercise in the identification of issues and in distinguishing between questions of fact, law and professional ethics.

Of particular value in this study is the insight afforded to the students into the natural inertia of civil servants. Early on in the study, when the basic facts have been presented, each student is asked to put in writing his general aims in handling the case. Almost invariably he writes that he wishes to obtain additional compensation for 'Kariuki'. He is then posed with an overnight problem to draft the next letter on the file. In doing this, to refuse further compensation is short and simple; to advocate further compensation involves detailed work. Frequently a student goes back on his stated aim and refuses further compensation. When the inconsistency is pointed out the following day, a good deal of amusement and understanding can result.

The second case study concerns the resettlement of Kenya Africans at Mpanda in the Western Province of Tanganyika. The operation begins in great haste when the Tanganyika Government starts repatriating to Kenya some of the Kenyans who had migrated into the Northern Province of Tanganyika. As an alternative to repatriation, it is agreed that these Kenyans might be settled at Mpanda. Later the scheme is expanded to include landless Kikuyu direct from Kenya. Many difficulties, misunderstandings and muddles arise, and the file is built up in all its complexities with irrelevant as well as relevant material. Each student takes on the job of the Deputy Secretary who is responsible for the operation. The action required individually of the students can include drafting 
a circular to Provincial Commissioners, replying to a Treasury query, writing a delicate letter to a senior politician, and drafting a reply for a Kenya Minister to a Tanganyika Minister when an inter-territorial disagreement cannot be resolved at a civil service level. The study provides many opportunities for analysing estimates and interpreting difficult passages of English. Onc of the climaxes comes at a point where senior civil scrvants disagree on the implications of a number of letters when read together. Discussions on issues of this sort are always lively, and effective argument has to be based on a mastery of intricate detail. There is no 'school solution' of the problems, and as the project has continued up to the time of writing, it has always been possible to end the study with fresh papers only a few days old. One student, who at the end of his coursc was posted to the Ministry concerned, went straight to the file and wrote a minute on it, which now appears in the up-to-date study. Although this is a casc of the observer changing the thing he is observing, it adds to the interest of the case.

In the presentation of these two case studies, emphasis is placed on individual action by the student. It is true that during the classroom sessions much of the time is taken up with syndicate discussions, both because of the value of the exchange of ideas and because it is impossible to correct written work in the middle of a session and at the same time maintain the flow and momentum of the study. But overnight problems are always individual. This arouses the student's interest in that he fecls himself competing against the actual officer concerned. It gives him practice in writing minutes and letters. It forces him to clarify his idcas and makes it difficult for him to coast through the stzidy. It helps him to develop confidence in his own - as opposed to his syndicate's - ability to handle situations. Above all, it makes him think, dccide and act on his own. In short, he develops 'inner-directed' skills, without which he would drift instead of steer his way through the complications of the case study.

The procedure with these overnight individual exercises is as follows: the minute or letter which has to be written is drafted by the student overnight. The drafts are collected first thing on the following morning, and corrccted. Selected pieces of work can be typed and transferred to a trunsparency to be shown to the class with an overhcad projector. Extracts from drafts which demonstrate good or bad English are written up on a blackboard, where they can be criticized by the students themselves, The corrected drafts are handed back and discussed, and then comes the exciling moment when the next papers on the file are issued, and each student sees what the officer in the real situation wrote and compares it with his own work. The actual minute or letter is never held up as a model of excellence but simply presented as one way of dealing with the problem.

With later and more senior courses for officers at Under-Secretary or equivalent level, this procedure was varied, and several copies were typed of each of the students' drafts. These were given code numbers, and assessed and criticised by syndicates, only the author knowing which was his letter. On this occasion, students proved far more outspoken in their criticism than any tutor would have been.

In addition to these longer individual exercises, shorter ones are given in the middle of a session. Short mathematical problems arising out of the material are particularly suitable and can be used as an oblique way of drawing attention to some vital fact that is being overlooked or of keeping the discussion on the ground. These shorter problems have the advantage of introducing a new 
activity in the middle of a scssion and of keeping students on their toes,

Despite this emphasis on indiviclual exercises which appears to be greater than is practised elsewhere, most of the appraisals and decisions mado in the classroom are nccessarily the work of syndicates,

Much of the success of a case study has been found to depend on the careful selection of syndicates. They must be balanced so that they are all of roughly the same strength. It is better to distribute the more talkative and more perceptive students evenly between the groups than to put them together. In this way, the syndicates will produce solutions of roughly the same calibre, and the weaker students will be able to leam from the more able.

The number of students per syndicate deserves careful thought. After a number of experiments, the writer has come to the tentative conclusion that for case studies of this type the best number of students in a syudicate is five, with three as a second best. In a group of six or more there are usually two or more students who hardly participate at all, With four there is a tendency for the discussion to polarize between the two strongest members, and the chances are two to one, with a square seating arrangement, and that they will sit next to one another rather than oppositc, so that the weaker two will be sitting away on one side of the main axis of discussion. In contrast, in a group of three, sitting equally spaced as though at the comers of an cquilateral triangle, the weakest member is closer to the main line of talk, and whon the two stronger members disagrce, holds the balance and is appealed to for support. The weakest man is thus drawn into the discussion automatically and may well find himself forced to make decisions. A group of three involves the students in considerable activity but has the disadvantage that the spread of ideas, attitudes and experience is limited. A five is more diverse and complex, and usually at least three members emerge as active talkers. With more variety than a three, and lacking the sterilc symmetry of a four, a five tends to remain flexible without falling into a standard pattern of interaction.

The number of syndicates into which the class is divided is also important, Two syndicates may not provide enough variety of decision for uscfil discussion, and it is unsatisfactory if one syndicato proves to be much more competcnt than the other, Four syndicates take a Iong time to debrief after their discussions, and may present such a range of decisions that the discussion becomes dispersed and lacking in direction. Three syndicates is idcal, allowing a useful but not confusing variety of decision and not taking too long to debrief.

The system of debriefing after a discussion may be varied. On their own, spoken reports from rapporteurs are unsatisfactory, tending to be woolly and to take a long time. A spoken report, summarised by the tutor as it gocs along, using either the blackhoard or, more casily, an overhead projector, is better. The writer, however, prefers a system in which cach rapporteur chalks up his syndicate's decisions on the blackboard. This introduces movement into the room, and often leads to members of a syndicate actively criticising and correcting their rapporteur as he writes. Were he presenting a spoken report, the members of the syndicate would be less likely to interrupt, and it would be easier for him to 'get away' with inaccuracies. This system also saves time, since all the rapporteurs can write simultaneously. Further, it provides a break in the session, usually with some relaxation on the part of the students after the concentration of their discussions.

Once the decisions have all been written up, discussion can follow. After a little training and prompting, students will force one another to specify the 
means of communication that are to be used in executing decisions, a gap in the comprehensiveness of the decisions which often appears at first. Finally, after discussion and mutual criticism between the syndicates, each student is issued with the papers which show what was done in reality. For the sake of clear comparison, the tutor may write this action up on the blackboard alongside the decisions of the syndicates.

It has been found an advantage to have all the syndicate discussions taking place at the same time in the same room. When separate rooms are used, discussion tends sometimes to flag. In the same room, however, the noise generates excitement and a competitive atmosphere and stimulates discussion. Only rarely has it been found that one syndicate overhears and uses something said in another syndicate. Concentration in one room also has the advantage that it is easier for the tutor to observe how the discussions are going, and to bring them all to a close at the same time. Rarely, if at all, should it be necessary for the tutor to participate in a group discussion, since such participation gives the group the feeling that there is an outside authority to whom appeals can be made when a difficulty has to be faced.

Undike many case studies used elsewhere, these two are not 'written'. In a written case study, an element of the fictitious must usually be introduced, even when the case study is based on a real situation. A written case study can be carefully contrived to serve a particular purpose, but it is doubtful whether this advantage often outweighs the drawbacks. In a written case study the unreality is liable to tempt the student into asking for more information, and even if the tutor is able to supply this, whether through careful preparation or through improvisation an air of artificiality is introduced. The student may even attack the whole frame work of the case study on the grounds that "people just don't behave like that" or "it couldn't have happened like that", In contrast, the beauty of taking a real live file, as with "Kariuki's Complaint" and "Mpanda Resettement", is that all the information required for action is on the file, and no one can be led astray into criticising the reality of the situations presented.

Many case studies used elsewhere are relatively short, taking only an hour or two; and a number of such case studies have been developed at the Kenya Institute of Administration. For instance, the "Shimba Hills Game Reserve" case study shows the progress of a development proposal through the various levels of Government. Another study, called "What's Your Line?", has been prepared in collaboration with the University of East Africa, and deals on an East African level with the problem of realigning an interterritorial railway line.

Short case studies sometimes have disadvantages. One is that information may have to be summarized, simplified or skated over rapidly, thus depriving the student of exposure to the facts in their full complexity and of the challenging task of analysing and using them. Another is that time may be too short for the appreciation of problems in depth. Again, the need to cover the ground quickly may make individual exercises impossible. Nevertheless, short case studies, designed for specific purposes, can be useful in presenting a wide variety of situations and problems.

The two main case studies discussed above are relatively long: "Kariuki's Complaint" takes four sessions of two hours each, with three overnight exercises. "Mpanda Resettlement" can vary in length, but usually takes ten two-hour sessions, with a variable number of overnight exercises. Long case studies like these allow the tutor flexibility. Often the most valuable discussions arise 
spontaneously and unexpectedly, and a tutor who is tied to a tight time-table may not have enough time to allow such discussions to flourish. There is much to be said for the tutor to some extent playing the case study off the cuff and varying the pace to suit the students and the material. It is an advantage to have at least two points in the study at which the session can be terminated, and for the tutor to decide only at the last moment which of the points he will use.

Too much must not be claimed for the techniques outlined above. Little in them, if anything, is original. They have evolved from ideas drawn from a number of sources, and have been adapted to the special needs of training administrators in a developing country. For the older, more experienced, but less well-educated students, they provide an exacting training in reading and comprehension, and might profitably be combined with use of the quicker reading films which are being developed at the Kenya Institute of Administration. For the younger, better educated but less experienced student, they provide an insight into the way the Government machine works and administrators act. For all students they provide practice in the exercise of judgment and in decision-making. They are essentially practical and directly related to the sorts of job that the students can expect to be doing when they finish the course. Above all, they enable the students to develop the skills they need in order to hold down jobs previously performed by expatriates with longer experience or greater education. Wherever urgent programmes are mounted to train administrative officers quickly to assume considerable responsibility, these techniques may prove to be of use. 